Journal of Social Sciences 4 (3): 165-172, 2008

ISSN 1549-3652

(C) 2008 Science Publications

\title{
Determinants of Success within an Integrated Business Curriculum Context: An Econometric Assessment
}

\author{
Ismail H. Genc and Selahattin Bekmez \\ Department of Economics, School of Business and Management, American University of Sharjah, \\ P.O. Box 26666, Sharjah, United Arab Emirates \\ Mugla University, IIBF Iktisat Bolumu, Kotekli Mugla, Turkey
}

\begin{abstract}
This paper studies an ongoing curriculum innovation at the College of Business and Economics at the University of Idaho, with junior level economics and business classes under one common team taught course, the Integrated Business Curriculum (IBC), instead of independent classes. In our study, there were six modules (classes) within IBC. The students were required to form teams, along with several other individual based academic activities. Faculty mentors provided guidance throughout the process. The student's success in IBC, measured as the grade obtained in modules, might be affected by a host of factors such as his/her own academic capacity, proxied by the pre-IBC GPA, the mentor's impact, proxied by his/her experience in the program, and the team impact, controlled by a dummy variable. To determine exactly what causes a student's success is absolutely important since the program continuously seeks to improve in a professional style with academic considerations, which was missing from the relevant literature on IBC. The data were collected from three different modules in 2001 Spring semester. After quite a few diagnostics tests in accordance with the econometrics and with the help of heteroskedasticity consistent estimation method, we searched for the factors affecting the student's success. We also conducted ordered logit/probit analyses as an alternative modeling of the grades for several reasons explained in the study. At the end, we found that the most significant factor in determining the success in IBC was still the student's own academic skills, while mentors did not differ from each other in contributing to the dependent variable. We also provided other relevant statistics and graphs supporting the findings.
\end{abstract}

Key words: Integrated/Undergraduate Business Curriculum, Team teaching, Course design JEL Classification: A22, C21, C25

\section{INTRODUCTION}

The integration idea of a common body of courses seems to have taken a firm root within the academic as well as professional business community. In recent years, the American Assembly of Collegiate Schools of Business (AACSB) actively promoted such a change in direction, without which the traditional business education could be out of touch with the business world reality as warned by the president of AACSB Smith ${ }^{[22]}$. Hawawini ${ }^{[9]}$ further cautions that traditional business schools can only survive if they heed calls of the business world where case studies are not enough for learning business. Alternatively, students could shadow actual businesses to gain experience in the field McCarthy and McCarthy ${ }^{[14]}$. In fact, actual business environment should be simulated in the educational material for business students. Yet, this is a challenge on a number of fronts Moratis and Hoff ${ }^{[17]}$. On the bright side, we know that students tend to learn relevant information more easily than the irrelevant one. The trick is to convince the learner's brain that what it is exposed to is relevant Bowett ${ }^{[2]}$. Needles to say, for business students, actual business environment presents the most relevant setup. This is further justification for bonding the practical business out in the field with the business education in schools. Likewise, Braun ${ }^{[3]}$ suggests that critical thinking must be incorporated into the business education curricula as it is demanded by the business world. On a related note, Reuben and Festervand $^{[20]}$ observe that MBA programs have become high tech intensive and for-profit.

The urgent issue at hand, therefore, becomes analyzing and devising effective methods for instructors

Corresponding Author: Ismail H. Genc, Department of Economics, School of Business and Management,

American University of Sharjah, P.O. Box 26666, Sharjah, United Arab Emirates

Tel: (971) 6-515-2327 Fax: (971) 6-515-2550) 
to employ in educating business students. The literature on various "innovative" teaching methods, which is far too many to list all here, has grown dramatically as a response to demands for change. However, many studies concentrate on devising methods in business schools to improve the managerial skills of the graduates (see, among others, Pharr and Morris ${ }^{[18]}$ Byrne $^{[4]}$ and Lataif ${ }^{[11]}$ ). The arguments about the improvement usually focus on adapting a system that has cross-functional integration or interdisciplinary and team-based approaches to business problems Miller ${ }^{[15]}$.

The starting point, which is almost common to all, is the idea that the business students should learn the management in a team-based environment, not in the traditional textbook way. Most of the companies are dissatisfied with the education and research coming out of graduate level business programs and thus a growing number of companies prefer in-house trained employees Leonard ${ }^{[12]}$. This, however, may bring substantive costs on companies to bear. Also, as Mintzberg $^{[16]}$ points out, the graduates of business schools are parachuted into mid-level companies with authority over people who have vast knowledge in business and customer relations and thus creating two tier employees: A boss with education, but not enough knowledge on one side and an employee who knows the customers, market conditions and business environment on the other.

This, in no way, means that everybody has dropped the so-called traditional teaching models, which are favored in some fashion or another by some such as ${ }^{[6,10 \text {, }}$ $13,19,23]$ due to problems created by the newly invented methods such as teacher knowledge, assessment and commitment from the faculty members and involved institutions.

In spite of the tremendous efforts spent on the pros and cons of the innovative business education methods, which are mostly integrative in nature, for the postgraduate success, not much attention seems to have been paid to the dynamics/factors which determine the likely success of students in the program while they are exposed to a demanding and relatively new educational environment. Especially lacking is the quantitative evaluations of the topic. As a matter of fact, to the best of our knowledge, our study will be one of the first or among the pioneers in the field, certainly so for the case study that we consider, viz. the Integrated Business Curriculum, IBC, experience at the College of Business and Economics in the University of Idaho.

IBC program at the university of Idaho: A faculty team in IBC teaches a set of junior level business courses in an interdisciplinary and cross-functional manner. Economics was originally part of the program.
Table 1: The contents of IBC and the relative weight in each module

\begin{tabular}{llllll}
\hline & Module 1 & Module 2 & & Module 3 \\
& -100 & 100 & 100 & 100 & 100 \\
\hline Tests & 100 & & & 100 & \\
\hline WSJ & & 25 & 50 & & \\
Project & 25 & 50 & & & \\
Tools & 50 & & & & \\
\hline
\end{tabular}

The numbers in the cells give the percentage of total available points from each testing material allocated to each module

However, IBC goes through constant evaluations and improvements. Therefore, in the most recent format, Economics is taken out of the main body of IBC, also as a response to staffing concerns, but its content is taught as a separate course in coordination with IBC. Accounting, too, has been incorporated into the system in a manner similar to that of Economics. The whole program on an hourly basis for the entire year is developed by the faculty team meeting during the summer. It normally is spread over two consecutive semesters. But in this study we will concentrate on the second semester for which we have the whole data set.

Students take five essay and problem solving tests during the semester, which are graded on the individual basis. They are also required to show computer proficiency on the individual basis. Students prepare a term project and make an oral business presentation, Wall Street Journal Presentation, as a team, which may have from 4-6 members. Presentations are done on a randomly determined order during the semester. Faculty act as mentors to teams assigned to them on team based assignments. Students may be in AM or PM sections of the program. The relative weight of each item corresponding to student's grade in each module is shown in Table 1.

Several concerns arise as a result of this set-up. First of all, students' grades are dependent on the success of the team they are in rather than exclusively on their efforts, which might be the standard in a standalone traditional alternative. The order the presentations can have an impact on grades, as well. Hence, one of the issues that IBC faculty constantly faces is the fairness/efficiency of presentations being delivered on different dates. An early presentation may be less desirable in terms of time available to prepare the material and later presentations can benefit from the earlier ones. But a late presentation may also mean restricted time available for tests which come toward the end of the semester.

Mentoring could also pose a threat of unfairness. Maybe an experienced mentor could provide a much better and informed guidance for his or her team compared to a team mentored by a faculty new to the 
program. Or maybe, the more seasoned faculty would behave more professionally than the new ones in acting in a more professional way since the former would feel less personal attachment to the team he or she guides compared to the latter.

Less worrisome may be the section the student is in. Unless the students prefer the morning to afternoon classes or vice versa, it may not be a real concern. However, afternoon section may carry over the diminishing pleasure of repeating the same material on the part of the faculty. The fatigue is another factor which may affect the performance of the faculty if he or she is supposed to teach for a good portion of the day, which may eventually translate into a significant effect on students' success. Fatigue and diminishing pleasure may also show on the part of the students as a result of attending other classes in the morning.

In a stand alone course, the student's success is almost solely dependent on his or her ability, ceteris paribus. It is interesting to see if this feature is preserved in an integrated business environment which has quite a few team based components.

In this research, we try to address these issues by considering the relative impact of likely variables in determining students' success in each module of the IBC.

Materials and Methods: The data come from the IBC Boeing Team at the College of Business and Economics of the University of Idaho during the Spring 2001 semester. The data set consists of slightly above 120 students in two sections, which is nearly half of them in each section. We have eliminated the repeat students, who do not necessarily conform to the IBC structure, leaving us with 117 observations (students). The summary statistics of the variables are shown in Table 2 except for the dummy variables.

We would like to determine the factors contributing to the student success in each IBC module, which is measured by the grade in that module. There are three modules in the semester in question. The average grade in each module is in mid-B level where the lowest grade was D with a standard deviation of about 7.95 .

We test the impact of faculty by incorporating their experience in the IBC program. The experience of the faculty is measured with the semester of the faculty spent in the program. Of the six persons, the experience variable takes on these values: One faculty has 2 semesters of experience, two faculty have been there for 8 semesters, other faculty taught 10, 12 and 14 semesters each. As in Tay ${ }^{[24]}$ the individual ability of each student is measured by his or her GPA entering the
Table 2: Descriptive statistics of the variables

\begin{tabular}{llllll}
\hline Variables & G343 & G344 & G345 & MENTOR & GPA \\
\hline Mean & 86.84 & 84.27 & 85.44 & 8.67 & 3.12 \\
Maximum & 101.13 & 100.21 & 99.15 & 14.00 & 4.00 \\
Minimum & 65.31 & 61.92 & 60.19 & 2.00 & 1.33 \\
Std. Dev. & 7.59 & 8.52 & 7.74 & 3.95 & 0.62 \\
Observations & 117 & & & & \\
\hline
\end{tabular}

semester (Fall 2000 GPA scores), which we call preIBC or entering GPA scores for the lack of a better term. Spring 1999 GPA scores did not produce statistically different results. The average GPA is 3.12 with a 0.62 standard deviation.

In sum, we measured the students' success in IBC as the grade obtained in modules, which might be affected by a host of factors such as his/her own academic capacity, proxied by the pre-IBC GPA, the mentor's impact, proxied by his/her experience in the program, the team impact and the section of the IBC, controlled by dummy variables. The effect of presentations is captured by the simple arithmetic ordering of them. To determine exactly what causes a student's success is absolutely important since the program continuously seeks to improve in a professional style with academic considerations, which is missing from the relevant literature on IBC. Table 3 shows the lower diagonal of the correlations among all the explanatory variables. As is clear from the table, the variables are statistically independent of each other, a requirement of successful applications of the econometric methods used in the rest of the study.

Results and Discussion: The empirical model we estimate is:

$$
\begin{aligned}
& \mathrm{Gj}=\mathrm{G}(\text { Section, Presentation order, } \\
& \text { Mentor Experience, Team, GPA) }
\end{aligned}
$$

where $\mathrm{Gj}$ is the numerical value of grades obtained in each module. Because there are three modules, $\mathrm{j}$ takes on 343,344 and 345 representing modules. Section is a dummy variable indicating the AM vs. PM IBC section. Presentation order runs from 1-10 to indicate the order of Wall Street Journal presentations. The experience of the mentor, Mentor Experience and GPA are as explained above.

Since we use dummy variables for Teams, we try all different combinations of 'dummying' the teams for the sake of robustness. This is a very demanding task given the possible combinations since we have a large number of teams. Thus, we have tried 16 different variations of assigning the dummy indicators to the teams to make sure the results were not altered as we change the dummying, which is what we obtained. 
Table 3: Correlations among the explanatory variables

\begin{tabular}{lrrrrl}
\hline & \multicolumn{1}{c}{ Section } & \multicolumn{1}{c}{ present } & mentor & team & gpa \\
\hline Section & 1.000000 & & & & \\
Present & -0.023120 & 1.000000 & & & \\
Mentor & 0.017400 & -0.158980 & 1.000000 & & \\
Team & -0.178879 & -0.350049 & -0.154595 & 1.000000 & \\
Gpa & -0.016689 & 0.189753 & -0.165305 & 0.044165 & 1.000000 \\
\hline
\end{tabular}

The most widely used technique in the literature seems to be testing the linear relationship between the dependent and independent variables. This means that a change in any of the independent variables would have the same effect on all observations of the dependent variable in a linear fashion. The ordinary least squares method or its variants are employed in this effort. The use of this method makes sense given the ease in its computation and the wide use which allows the comparison to other studies. Hence, we take this route as the first step of this research. However, one can argue that a linear relationship between variables concerned might be quite restrictive as the behavior of an A student to a change in any independent variable would not be quite exactly the same with an F student, for example. That argument brings us to the second step of our estimation taking into account the possible non-linearities in the relationship which is expressed in Eq. 1.

Thus, our first attempt is to run an ordinary least squares regression, OLS, for the above equation. We do not report the results here, which are available from authors upon request, but rather present a discussion regarding the robust estimation issues which must be a concern for empirical economists using OLS. Specifically, Davidson and MacKinnon ${ }^{[7]}$ warn researchers on the possibility of influential observations, which may drive the empirical results. Following their advice, we calculate the OLS residuals, $\mathrm{u}$ and $\mathrm{h}$ statistics as suggested by Belsley, Kuh and Welsch $^{[1]}$ together with the influence measure, $u h /(1-h)$, to detect the possibility of certain observations leading the unexpected results, i.e., the influential observations. The results of this endeavor are to be found in Table 4 and Fig. 1. The theoretically expected average value of the $\mathrm{h}$ statistics is $\mathrm{h}_{\mathrm{T}}=\mathrm{k} / \mathrm{n}=6 / 117=0.0513$ for all regressions and values above $2 \mathrm{k} / \mathrm{n}=0.1026$ must ring the alarm bells. We find that there are only two observations in each regression which surpass twice the theoretically expected average although the ratio of the maximum $h, h_{\text {MAX }}$, to the minimum value of $h, h_{\text {MIN }}$, is quite large. However, as the graphs of the variables show, Fig. 1, none of these observations seems to be influential on the results. Hence, dropping them do not change the coefficients in estimations, except the
Table 4: Influential observations analysis

\begin{tabular}{llll}
\hline & $\mathrm{H} 343$ & $\mathrm{H} 344$ & $\mathrm{H} 345$ \\
\hline Maximum, $\mathrm{h}_{\text {MAX }}$ & 0.138200 & 0.138300 & 0.112100 \\
Minimum, $\mathrm{h}_{\text {MIN }}$ & 0.019200 & 0.019200 & 0.017900 \\
$\mathrm{~h}_{\mathrm{T}}$ & 0.10256 & 0.10256 & 0.10256 \\
$\mathrm{~h}_{\mathrm{i}} \geq \mathrm{h}_{\mathrm{T}}$ & 2 & 2 & 2 \\
$\mathrm{~h}_{\mathrm{MAX}} / \mathrm{h}_{\text {MIN }}$ & 7.197917 & 7.203125 & 6.26257 \\
\hline
\end{tabular}

coefficient of Section in G345 regression, which changes from negative to positive, but in an insignificant manner.

Armed with the soundness of observations in the data set, we tested for the existence of the heteroskedasticity problem, which is common in crosssectional data sets. A quick look at the plots of dependent variables against independent variables indicates the existence of heteroskedasticity. The range between the two consecutive values of the dependent variable increases as the value of the independent variables, for example GPA, increases. Further statistical tests also point to the same direction. To this end, we run

$$
\mathrm{e}_{\mathrm{t}}=\mathrm{f}(\mathrm{X})+\Sigma \beta_{\mathrm{j}} \mathrm{e}_{\mathrm{t}-\mathrm{j}}+\Sigma \phi_{\mathrm{j}} \mathrm{X}_{\mathrm{j}}+\Sigma \delta_{\mathrm{j}} \mathrm{X}_{\mathrm{j}} \mathrm{X}_{\mathrm{i}}
$$

where $\mathrm{i}, \mathrm{j}=1, . ., 4$ and $\mathrm{i} \neq \mathrm{j}$. e is the error from the OLS regression of Eq. 1. $\mathrm{X}$ is the vector of explanatory variables. The $\mathrm{TR}^{2}$ values obtained from this regression testifies to the existence of the heteroskedasticity, at least in the first two estimations. Here $\mathrm{T}$ stands for the number of observations in each regression.

A more sound method to estimate a relationship among a set of variables in the presence of heteroskedasticity is suggested by White ${ }^{[25]}$ by employing the heteroskedasticity consistent covariances. The results are presented in Table 5. A few comments are in order.

Although it has inconsistent coefficient estimates, the Section is not a statistically significant variable in contributing to the grade obtained in each module. However, Presentation order seems to positively contribute to the grade in all three modules, albeit in a relatively small scale. This could/should be a concern for the faculty in arranging the order of presentations. In the format under consideration here, the presentations were spread throughout a good portion of the semester creating a big time space between the first and the last presentation. Some of the suggestions might be putting all the presentations in a time wise relatively short span from each other to provide a level playing field for all students. 

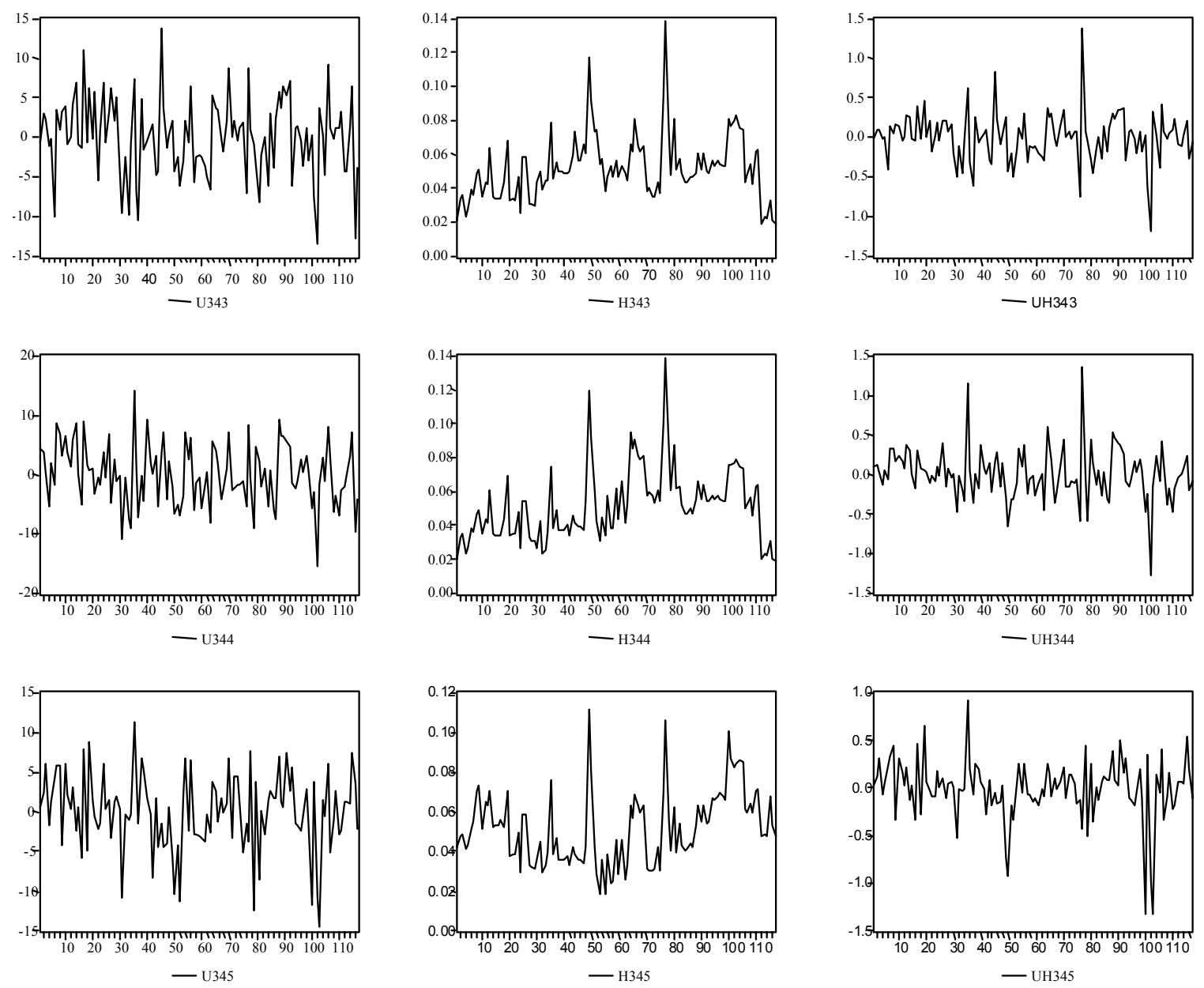

Fig. 1: Graphs of $\mathrm{u}$ (residuals), $\mathrm{h}$ and $\mathrm{uh} /(1 \mathrm{~h})$

Table 5: White's heteroskedasticity consistent estimation results

\begin{tabular}{llll}
\hline Variables & G343 & G344 & G345 \\
\hline $\begin{array}{l}\text { Section } \\
\begin{array}{l}\text { Presentation } \\
\text { order }\end{array}\end{array}$ & $0.728(1.703)$ & $-1.127(-1.096)$ & $-0.535(-0.541)$ \\
Mentor & $0.015(0.119)$ & $0.037(0.270)$ & $0.259(1.791)$ \\
semesters & & & \\
Team & $0.008(0.088)$ & $-0.064(0.694)$ & $0.116(1.373)$ \\
GPA & $8.509(9.350)$ & $10.352(9.856)$ & $8.253(8.650)$ \\
min R2 & 0.557 & 0.547 & 0.547 \\
max R2 & 0.562 & 0.635 & 0.594 \\
TR2 & 21.08039 & 22.21640 & 39.68497 \\
& $(0.332376)$ & $(0.273619)$ & $(0.003598)$ \\
F & 26.82 & 35.28 & 30.04 \\
Observations & 117 & 117 & 117 \\
\hline
\end{tabular}

White Heteroskedasticity-Consistent Standard Errors and Covariance $\mathrm{t}$ stats in parentheses

Perhaps the biggest worry among the faculty as well as the students is the mentor factor. Both students and faculty do not want to punish or reward a team simply thanks to a mentor, who is assigned to teams randomly. We are glad to see that even though a positive coefficient on the mentor variable is found, it is not a statistically significant one for all three estimations of module grades. Another biggest contention is the team factor. It is well-understood among the faculty that teams are an abstraction of reality, some students may not seem to appreciate to be in a team mainly because of the fear of free riders. Students are allowed to form their teams themselves in the IBC, which may not exactly correspond to a real life application, but then again a few teams seem to produce more antagonism than lifelong friendships among its members. Nevertheless, our linear estimations do not support the idea that team is a statistically significant factor in determining one's grade in any module.

On the contrary, we find that by far the most significant factor in determining one's module grade is his/her own ability, which is proxied by the entering GPA in all regressions. Not only that the coefficient on 
GPA turns out to be statistically significant, it is the largest coefficient in all regressions.

All estimations seem to explain well over $50 \%$ of the variation in the dependent variable as measured by the $\mathrm{R}^{2}$ values and the coefficients altogether can not be dropped from the estimations in favor of a constant only, which basically means that our model in explaining the factors in module grades is working under the conditions specified above.

An Ordered Logit/Probit Analysis: An Alternative Approach: Even though the ordinary least square method is widely employed in the literature to estimate student performance Tay ${ }^{[24]}$, we also include here an alternative modeling of the issue. The basic argument against measuring the student performance as a continuous variable as in the OLS case above is that for a student there is no difference between 90 and above since all translate into the same letter grade, producing discrete observations for the dependent variable. Likewise for other numerical grades. Thus, the performance should rather be thought of as a ranking (ordering) of the letter grades. The empirical approach which makes a prominent use of modeling ordered discrete choices, especially in marketing applications, is the ordered logit and/or probit analyses. Greene ${ }^{[8]}$ provides the sketch of the method. Examples of financial applications can be found in Campbell et al. [5].

The additional support in favor of the ordered choice analysis is based on the fact that the relationship between the dependent variable and the independent ones is treated linear in OLS, making the impact of a change in any independent variable to the dependent one uniformly distributed over all observations of the dependent variable. However, as alluded to above, the reaction by an $\mathrm{F}$ student as opposed to an A student, for example, to a change in any independent variable might be quite different.

Thus, we recode the grades as $90+, 80-89.99,70-$ 79.99, 60-69.99 and less than 60 with $0,1,2,3$ and 4, respectively, which constitutes the dependent variable. In a sense these breaks in letter grades make up the grade categories. The independent variables remain as before. We reestimate Eq. 1 with logistic and standard normal distribution as the functional form, G. The marginal effects as a response to changes in independent variables produced that way become nonuniform over the sub-categories of the dependent variable. The form of the marginal effects can be stated as follows:

$$
\begin{aligned}
& \partial \operatorname{Pr}\left(\mathrm{Gj}_{\mathrm{i}}=0\right) / \partial \mathrm{x}=-\mathrm{f}\left(-\mathrm{x}_{\mathrm{i}}{ }^{\prime} \beta\right) \beta \\
& \partial \operatorname{Pr}\left(\mathrm{Gj}_{\mathrm{i}}=1\right) / \partial \mathrm{x}=\left[\mathrm{f}\left(-\mathrm{x}_{\mathrm{i}}{ }^{\prime} \beta\right)-\mathrm{f}\left(\gamma_{1}-\mathrm{x}_{\mathrm{i}}{ }^{\prime} \beta\right)\right] \beta \\
& \partial \operatorname{Pr}\left(\mathrm{Gj}_{\mathrm{i}}=2\right) / \partial \mathrm{x}=\left[\mathrm{f}\left(\gamma_{1}-\mathrm{x}_{\mathrm{i}}{ }^{\prime} \beta\right)-\mathrm{f}\left(\gamma_{2}-\mathrm{x}_{\mathrm{i}}{ }^{\prime} \beta\right)\right] \beta \\
& \partial \operatorname{Pr}\left(\mathrm{Gj}_{\mathrm{i}}=3\right) / \partial \mathrm{x}=\left[\mathrm{f}\left(\gamma_{2}-\mathrm{x}_{\mathrm{i}}{ }^{\prime} \beta\right)-\mathrm{f}\left(\gamma_{3}-\mathrm{x}_{\mathrm{i}}{ }^{\prime} \beta\right)\right] \beta \\
& \partial \operatorname{Pr}\left(\mathrm{Gj}_{\mathrm{i}}=4\right) / \partial \mathrm{x}=\mathrm{f}\left(\gamma_{3}-\mathrm{x}_{\mathrm{i}}{ }^{\prime} \beta\right) \beta
\end{aligned}
$$

where $\mathrm{x}$ stands for the set of independent variables, $\beta$ estimated coefficients and $\gamma$ the limit conditions and $\mathrm{f}$ for the probability density function. In an OLS type analysis, 3a-3e would simply be $\partial \operatorname{Pr}(\mathrm{Gj}) / \partial \mathrm{x}=\beta$, underlying the uniformity in marginal effects from a linear model. As is clear from $3 \mathrm{a}$ and $\mathrm{e}$, the changes in $\mathrm{x}$ would cause a change in $\mathrm{Gj}$ in the same direction with the change in $\mathrm{x}$ for $\mathrm{A}$ students, but in the opposite direction for $\mathrm{F}$ students. 3b-d are ambiguous without the signs of all the expressions involved. A check on the validity of the expressions is that the sum of partial derivatives in 3 has to be zero, corresponding to the fact that cumulative density function sums up to one. In other words, Eq. 3 gives the pieces of the total derivation of a cdf.

The estimation results of both logit and probit analyses are presented in Table 6. For all modules in both methods, the findings correspond to the OLS results regarding the sign and significance of the variables as far as the Presentation order, Mentor experience and GPA are concerned. Only in the first module, namely 343, both Team and Section are statistically significant variables. Our conjecture is that there might be an adjustment process at work here since at least some of the teams are re-formed at the beginning of the semester and students might face some scheduling problems again at the beginning of the semester. We think all these problems clear over time. However, this explanation is clouded with the fact that the Team variable is still statistically significant in the last module.

As we mentioned before, the interpretation of the coefficients per se does not provide much of an explanation unless the correctly calculated marginal effects are stated. Most of the literature which uses the marginal analysis prefers to report especially the findings of the probit analysis ignoring the logit results, which is what we do in the rest of the study. We show in Table 7 the impact on the dependent variables of a one unit change in the independent variables which are found statistically significant in all three module grade estimations. As results testify a one unit increase in the entering GPA of the IBC students would lead to an increased likelihood of finding more A students within 
Table 6: Logit and Profit estimations

\begin{tabular}{|c|c|c|c|c|c|c|}
\hline \multirow[b]{2}{*}{ Variables } & \multicolumn{2}{|l|}{ G343 } & \multicolumn{2}{|l|}{ G344 } & \multicolumn{2}{|l|}{ G345 } \\
\hline & Logit & Profit & Logit & Profit & Logit & Profit \\
\hline \multirow[t]{2}{*}{ Section } & 0.972 & 0.499 & -0.095 & -0.092 & 0.323 & 0.189 \\
\hline & -2.311 & -2.12 & -0.413 & $(-0.392)$ & -0.778 & -0.803 \\
\hline \multirow[t]{2}{*}{ Presentation } & 0.157 & 0.093 & 0.211 & 0.121 & 0.212 & 0.131 \\
\hline & -2.195 & -2.226 & -0.076 & -2.79 & -2.776 & -3.045 \\
\hline \multirow[t]{2}{*}{ Mentor } & 0.054 & 0.037 & 0.028 & 0.013 & 0.026 & 0.02 \\
\hline & -0.979 & -1.88 & -0.055 & -0.438 & -0.465 & -0.642 \\
\hline \multirow{2}{*}{ Team } & -0.076 & -0.044 & -0.048 & -0.025 & -0.083 & -0.047 \\
\hline & $(-2.023)$ & $(-2.099)$ & -0.038 & $(-1.162)$ & $(-2.120)$ & $(-2.164)$ \\
\hline \multirow[t]{2}{*}{ GPA } & 3.009 & 1.653 & 4.102 & 2.277 & 2.975 & 1.67 \\
\hline & -6.303 & -6.933 & -0.575 & -7.904 & -6.253 & -6.706 \\
\hline$\gamma 1$ & 6.299 & 3.412 & 8.53 & 4.635 & 5.804 & 3.366 \\
\hline$\gamma 2$ & 8.753 & 4.762 & 11.321 & 6.211 & 7.741 & 4.453 \\
\hline$\gamma 3$ & 12.351 & 6.779 & 15.776 & 8.709 & 12.174 & 6.96 \\
\hline Number of Observations & 117 & 117 & 117 & 117 & 117 & 117 \\
\hline Log-Likelihood & -90.289 & -90.372 & -85.298 & -85.0146 & 1.667 & $-8.91 \mathrm{E}+01$ \\
\hline Restricted Log-Likelihood & -131.642 & -131.642 & 141.229 & -141.229 & -89.519 & -131.721 \\
\hline LR Statistics & 82.705 & 82.54 & 111.862 & 112.4288 & -131.721 & 85.311 \\
\hline Probability of LR Stat & 0 & 0 & 0 & 0 & $1.11 \mathrm{E}-16$ & $1.11 \mathrm{E}-16$ \\
\hline
\end{tabular}

$\mathrm{t}$ stats in parentheses

Table 7: The marginal effects of the probit model

\begin{tabular}{lllll}
\hline & & G343 & G344 & G345 \\
\hline $\mathrm{A}$ & GPA & 0.579 & 0.431 & 0.374 \\
& PRESENT & 0.033 & 0.023 & 0.029 \\
$\mathrm{~B}$ & GPA & -0.367 & -0.029 & -0.135 \\
& PRESENT & -0.021 & -0.002 & -0.011 \\
$\mathrm{C}$ & GPA & -0.201 & -0.386 & -0.211 \\
& PRESENT & -0.011 & -0.021 & -0.017 \\
$\mathrm{D}$ & GPA & -0.011 & -0.016 & -0.028 \\
& PRESENT & -0.001 & -0.001 & -0.002 \\
$\mathrm{~F}$ & GPA & $-1.93 \mathrm{E}-09$ & $-6.07 \mathrm{E}-13$ & $-2.01 \mathrm{E}-08$ \\
& PRESENT & $-1.09 \mathrm{E}-10$ & $-3.24 \mathrm{E}-14$ & $-1.58 \mathrm{E}-09$ \\
& SUM & 0.000 & 0.000 & 0.000 \\
\hline
\end{tabular}

the pool while less of F students. Our computations also show that this change decreases not only the probability of $\mathrm{F}$ students but also any non-A students. The same observation can be made for the Presentation order variable.

\section{CONCLUSIONS}

For the last several years, the College of Business and Economics at the University of Idaho has been implementing a quality award winning curriculum innovation, which incorporates junior level economics and business classes under one common team taught course, the Integrated Business Curriculum (IBC), instead of independent classes. There are six modules (classes) within the IBC. The students are required to form teams, along with several other individual based academic activities. Faculty mentors provide guidance throughout the process.

The student's success in the IBC, measured as the grade obtained in modules, might be affected by a host of factors such as his/her own academic capacity, proxied by the pre-IBC GPA, the mentor's impact, proxied by his/her experience in the program, the team impact, controlled by a dummy variable as well as a dummy variable controlling for the section the student is in. To determine exactly what causes a student's success is absolutely important since the program continuously seeks to improve in a professional style with academic considerations, which is missing from the relevant literature on the IBC.

The data set used in this study comes from three different modules in the 2001 Spring semester. We search for the factors which affect the student's success in the IBC by employing linear and non-linear methods of estimation where the former is represented by an ordinary least square (as well as heteroskedasticity consistent White ${ }^{[25]}$ method) and the latter found its applications via logit and probit functions.

We find that the most significant factor to determine the success in the IBC is still student's own academic skills, while mentors do not differ from each other in contributing to the dependent variable. Moreover, we could not find any statistical evidence to suggest globally that the section or a team a student is in makes a tremendous impact on his or her success in the IBC. We, however, suggest that faculty should be more cognizant of the oral presentation order assigned to students since it seems to have an impact on students' grade in the modules. Better performance can be obtained also in making sure that students are better prepared before they take on the IBC challenge, no surprise there. 
This study is obviously not free from imperfections. The least we can suggest for future is to repeat the same research on different cohorts of IBC as all the results above are based on the same semester's activity.

\section{REFERENCES}

1. Belsley, D., Kuh, E., and Welsch, R., 1980. Regression Diagnostics, Wiley: New York.

2. Bowett, R., 2005. How do I make business lessons relevant to students? Teach. Business Econ. 9, 3: 7-12.

3. Braun, N.M., 2004. Critical thinking in the business curriculum. J. Educ. Business, 79: 232-236.

4. Byrne, J. A. 1993, 'Harvard Business School: An American institution in need of reform', Business Week, (July 19), 58-65.

5. Campbell, J.Y., A.W. Lo and A.C. MacKinlay, 1997. The Econometrics of Financial Markets. Princeton University Press, New Jersey, $1^{\text {st }}$ edition.

6. Cotton, K., 1982. Effects of Interdisciplinary Team Teaching: Research Synthesis. Northwest Regional Education Lab, Portland, OR (ERIC Document Reproduction Service No. ED230533).

7. Davidson, R. and MacKinnon, J., 1993. Estimation and Inference in Econometrics, Oxford University Press: Oxford, $1^{\text {st }}$ edition.

8. Greene, W.H., 1997 Econometric Analysis. Macmillan Publishing Company, New York, $3^{\text {rd }}$ edition.

9. Hawawini, G., 2005. The future of business schools. The J. Manage. Dev., 24, 9: 770-782.

10. Jacobs, H.H., 1991. Planning for curriculum integration. Educ. Leadership, 49: 27-28.

11. Lataif, L. E. 1992, 'Debater in MBA: Is the traditional model doomed?', Harvard Business Review, (November/December), 70, 6, 128-140, \{one of the 13 commentaries on a previously published case study about the value of a MBA to employers today\}.

12. Leonard, E. W. 1992, 'Debater in MBA: Is the traditional model doomed?', Harvard Business Review, (November/December), 70, 6, 128-140, \{one of the 13 commentaries on a previously published case study about the value of a MBA to employers today\}.
13. Mason, T.C., 1996. Integrated curricula: Potential and problems. J. Teacher Educ, 47: 263-270.

14. McCarthy, P.R. and H.M. McCarthy, 2006. When case studies are not enough: Integrating experiential learning into business curricula. J. Educ. Business, 81: 201-204.

15. Miller, J., 2000. Economics in the integrated business curriculum. J. Educ. Business, 76: 113-118.

16. Mintzberg, H. 1987, 'Training Managers, Not MBAs', Paper Presented at the Macro Organizational Behavior Society, Northwestern University, (September).

17. Moratis, L. and J. Hoff, 2006. A dual challenge facing management education-simulations based learning and learning about CSR. J. Manage. Dev., 25: 213-231.

18. Pharr, S. and L. Morris, 1997. The fourthgeneration marketing curriculum: Meeting AACSB's guidelines. J. Market. Educ., 19: 31-43.

19. Pharr. W.S., S.J. Morris, D. Stover, C.R. Byers and G.R. Reyes, 1998. The execution and evaluation of an integrated business common core curriculum. J. G. Educ., 47: 166-182.

20. Reuben Kyle, R. and T.A. Festervand, 2005. An update on the high-tech MBA. J. Educ. Business, 80: 240-244.

21. Ruud, P.A., 2000. An Introduction to Classical Econometric Theory. Oxford University Press, Oxford, $1^{\text {st }}$ edition.

22. Smith, K.R., 1995. Individually and Collectively, Schools Need to Start Journey Toward Transformation. Address of President Smith to the AACSB 1995 Annual Meeting. St. Louis, MO.

23. St. Clair, B. and D.L. Hough, 1992. Interdisciplinary Teaching: A Review of the Literature. Springfield, MO: Southwest Missouri State University (ERIC Document Reproduction Service No. ED 373 056).

24. Tay, R.S., 1994. Students performance in economics: does the norm hold across cultural and institutional settings? J. Econ. Educ., 25: 291-301.

25. White, H., 1980. A heteroskedasticity-consistent covariance matrix and a direct test for heteroskedasticity. Econometrica, 48: 817-838. 